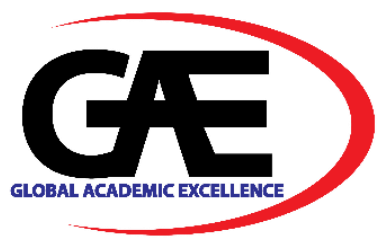

\title{
ARTIFICIAL INTELLIGENCE: IS IT A THREAT OR AN OPPORTUNITY BASED ON ITS LEGAL PERSONALITY AND CRIMINAL LIABILITY?
}

\author{
Mark Louis ${ }^{1 *}$, Angelina Anne Fernandez ${ }^{2}$, Nazura Abdul Manap ${ }^{3}$ Shamini Kandasamy ${ }^{4}$ Lee Sin \\ $\mathrm{Yee}^{5}$
}

1 Department of Accounting, Universiti Tunku Abdul Rahman, Malaysia

Email: marklouis@utar,edu.my

2 Department of International Business, Universiti Tunku Abdul Rahman, Malaysia

Email: angelina@utar.edu.my

3 Dean of Law Faculty, Universiti Kebangsaan, Malaysia

Email: nazura@ukm.edu.my

4 Department of Accounting, Universiti Tunku Abdul Rahman, Malaysia

Email: shamini@utar.edu.my

5 Department of Economics, Universiti Tunku Abdul Rahman

Email: leesy@utar.edu.my

* Corresponding Author

\section{Article Info:}

\section{Article history:}

Received date: 27.05 .2019

Revised date: 27.06 .2019

Accepted date: 11.02.2021

Published date: 01.03.2021

\section{To cite this document:}

Louis, M., Fernandez, A. A., Manap, N. A., Kandasamy, S., \& Lee S. Y. (2021). Artificial Intelligence: Is It A Threat or An Opportunity Based on Its Legal Personality and Criminal Liability?. Journal of Information System and Technology Management, 6 (20), 01-09.

DOI: $10.35631 /$ JISTM.620001.
Abstract:

Information technology is taking the world by storm. The technological world is changing rapidly and drastically. Human activities are taken over by robots and computers. The usage of computers and robots has increased productivity in various sectors. The emergence of artificial intelligence has stirred up many debates on both its importance and limitations. Artificial intelligence is directed to the usage of Information Technology in conducting tasks that normally require human intelligence. The expectation of artificial intelligence is high, nevertheless, artificial intelligence has its shortcomings namely the impact of artificial intelligence on the concept of a legal personality. The problem with artificial Intelligence is the debate on whether does it have a legal personality? And another problem is under what situation does the law treat artificial intelligence as an entity with its own rights and obligations. The objective of this article is to examine the various definitions of legal personality and whether artificial intelligence can become a legal person. The article will also examine the criminal liability of artificial intelligence when a crime has been committed. The methodology adopted is qualitative namely Doctrinal Legal Research by analyzing the relevant legal views from various journals on artificial intelligence. The study found out that artificial intelligence has its 


$\begin{gathered}\text { Journal of Information System } \\ \text { and Technology Management } \\ \text { EISSN: 0128-1666 }\end{gathered}$
Volume 6 Issue 20 (March 2021) PP. 01-09
DOI: 10.35631/JISTM.620001
ersonality and also in examining the criminal
mmitted by robots.

\section{Introduction}

Industrial Revolution 4.0 plays a big role in revolutionizing the importance of Artificial Intelligence. Artificial Intelligence is slowly taking the world. From work such as learning, problem solving, planning, decision making to specific tasks like chess playing, proving mathematical theorems and writing poetry and diagnosing diseases. (Russell, 1995) However, Artificial Intelligence is still at its infancy stage and its flaws need to be addressed. The use of Artificial Intelligence needs to be monitored closely to increase productivity and to minimize its complications. There are numerous incidents in which Artificial Intelligence pose a threat namely when Facebook's Artificial Intelligence created its own language that we can't understand and as a result Facebook was forced to be shut down their system due to the Artificial Intelligence starting to communicate with each other with unique languages. (Andrew, 2017). This proves that this system needs to be monitored closely as Artificial Intelligence is not ready yet to replace human capabilities. There are also incidents in which an Artificial Intelligence system malfunctioned. A recent case has occurred in the year 2016 whereby a Tesla autopiloted system caused a car crash. Tesla admitted that the autopiloted system was activated but it had failed to detect vehicles. (BBC news, 2016)

According to Oxford Dictionary Artificial Intelligence is defined as intelligence exhibited by machines. Google CEO Eric Schmidt stated in his conference that Artificial Intelligence will be a solution of wide challenges faced by humanity such as climate modelling, macroeconomics, particle physics, disease diagnosis, material sciences, drug discovery, theorem proving and protein folding. He derived three rules about Artificial Intelligence namely:

1. Artificial Intelligence will benefit many

2. The research in this technology is getting significant

3. The development in this system must be transparent and be monitored ( IEEE Spectrum, 2016)

Zooming into the problem, Kenji Urada was a lethal case caused by Artificial Intelligence. It occurred in a Kawasaki Heavy Industries plant whereby a Japanese worker was killed by an Artificial Intelligence robot in which the robot pushed him into a grinding machine. And Kenji's incident is the first lethal incident caused by a robot in Japan. (Robert, 2014) Another lethal case occurred on January 25, 1979 whereby a Ford Motor employee named Robert William was killed by a one-ton robot. The jury awarded $\$ 10$ million dollar as a monetary compensation to his heirs. Artificial Intelligence is divided into two namely strong Artificial Intelligence and Weak Artificial Intelligence. Strong Artificial Intelligence is the machine's ability to think, act, and communicate like a human being (Bringsjord and Schimanski,2003). Strong Artificial Intelligence is a machine that could possess human like mental state, it has self-consciousness and have the ability to act and behave by itself. Weak Artificial Intelligence on the other hand was designed merely to imitate the act of the human being to solve a problem or complete a task (Nilsson, 2006). An example of a weak Artificial Intelligence is Deep Blue Copyright $\odot$ GLOBAL ACADEMIC EXCELLENCE (M) SDN BHD - All rights reserved 


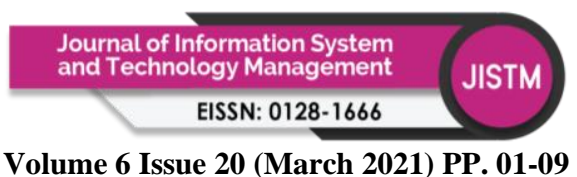

Volume 6 Issue 20 (March 2021) PP. 01-09

DOI: 10.35631/JISTM.620001

which was a program that is stimulating a chess player. The program was developed by computer scientist who work in IBM during the early 1990's. It was able to defeat Gary Kasparov the grand chess master one out of six times nonetheless it was categorized as weak Artificial Intelligence because it was only able to play Chess by simulating an action of a human being. It does not possess any other ability besides chess playing. Then came a breakthrough for the Artificial Intelligence technology when a humanoid name Sophia was created. According to (Weller, 2017) Sophia was the first humanoid who obtain citizenship by Saudi Arabia. Sophia is capable of human facial expression, verbal and nonverbal interaction.

According to the Dictionary of Law, Third Edition, a Legal Personality is defined as those qualities or characteristics of an individual, eg age, domicile from which are derived from his Legal status and capacity. Artificial person is defined by (Sinha and Dheeraj,1996)as an entity such as a corporation created by law and which is given certain attributes of a natural person and artificial is defined by (Sinha and Dheeraj, 1996) as a technical use of words having a special meaning in certain definite activities. The term "artificial person" means a legal entity ie; a corporation or any other group treated by law as a person. Legal personality as defined by (Sinha and Dheeraj,1996) is the status of corporate body whereby it may act as a natural individual in bringing or defending lawsuits and acquiring property, etc.

We are now in the Fourth Industrial Revolution and it is ongoing, a transformation which involves the usage of intelligent machines in our daily lives known as Artificial Intelligence. Artificial Intelligence is smart machines, robots that are used to speed up the task in our daily lives and make it more efficient. We were introduced to robots in Sci-fi movie like Terminator, Robocop and etc, but the reality is Artificial Intelligence models are being used in our workplaces. Experts predict that certain jobs, in which a lot of repetition takes place, will be mastered by Artificial Intelligence. This includes aspects of accounting, law, financial services and even routine surgery. Artificial Intelligence is intelligence generated by machines and is known as intelligent agents. These machines have brought about efficiency in productivity. Nonetheless, these intelligent machines have brought about also a lot of legal liability in terms of criminal liability and raise the question on its legal personality.

\section{Literature Review}

\section{$1^{\text {ST }}$ Legal Issue Faced by Artificial Intelligence Is Whether It has a Legal Personality of Its Own?}

To quote a dissertation for the Degree of Master of Philosophy, submitted in the University of Oxford, entitled: Legal Personality for Artificial Intellects: Pragmatic Solution or Science Fiction? Which was written by (Benjamin D Allgrove and Magdelen College,2017) they defined legal personality as follows:

"Legal personality is who counts for the purpose of law. The impact of artificial intelligence technology provides a unique opportunity to look afresh at this oft-misunderstood legal concept."

In this well written thesis, the author (Benjamin D Allgrove and Magdelen College,2017) refers to an article written by (AR Damasio,1994) which divides intelligence into two which are Weak Artificial Intelligence and Strong Artificial Intelligence.

To quote the author Strong Artificial Intelligence is 


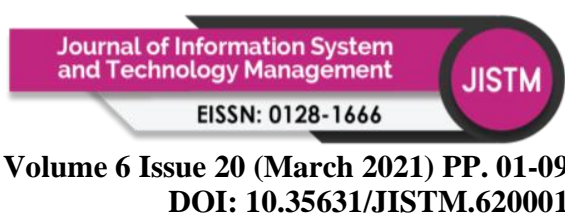

"Intelligence as encompassing the full capabilities and attributes of human intelligence computers actually thinking and is known as strong AI"

And the author Benjamin D Allgrove and Magdelen College goes on to state that Weak Artificial Intelligence is when the computer is simulating intelligence.

The burning question to Artificial Intelligence is does a legal personality exist in this model, that would appear to have intelligence but not having a conscience and is not alive but a machine that is programmed by software.

(Lawrence B Solum, 1992) a Professor in Loyola Law School in his essay entitled Legal Personality for Artificial Intelligences, stated that:

"No existing computer program currently possesses the sort of capacities that would justify serious judicial inquiry into the question of legal personhood. Cognitive science begins with the assumption that the nature of human intelligence is computational and therefore the human mind can in principle be modelled as a program that runs on a computer.

The author Lawrence made reference to (Owen J Flanagan, Jr.,1991) in which Artificial Intelligence attempts to develop such models. Professor Lawrence Solum also made reference to the work of Rene Descartes who first considered whether it was possible for a machine to think. To quote Descartes:

"For we can easily understand a machine's being constituted so that it can utter words and even emit some responses to action on it of a corporeal kind, which brings about change in its organs; for example, if it is touched in a particular part it may ask what we wish to say to it; if in another part it may exclaim that it is being hurt and so on, but it never happens that it arranges its speech in various ways, in order to reply appropriately to everything that maybe said in the presence, as even the lowest type of man can do."

From the author Descartes viewpoint, it can be deduced that machines are programs run by computers, incapable to reacting and thinking like humans and this machines are incapable of arranging its speech and actions appropriately like humans can do. A human being has been gifted with a mind to discern right from wrong and to react accordingly. Machines or artificial intelligence units are incapable to react accordingly to the surrounding circumstances and they perform the task based on their programs.

Alan Turing an English mathematician, a war time Code Breaker and the pioneer of computer science devised a question and answer game known as Can Machines Think?, in which it questions whether a candidate ( computer AI) has the ability to think and engage in a game of imitation with a human opponent. And surprisingly, it was reported by BBC news on $9^{\text {th }}$ June 2014 that a computer program called Eugene Goostman which was simulated by 13-year-old Ukranian boy named Vladimir Veselov, managed to pass the Turing Test in an event organised by University of Reading. The test examines on whether people can detect if they are talking to machines or humans. You can pass the Turing Test, if a computer is mistaken for a human more than $30 \%$ of the time by completing a series of five minute keyboard conversations and the computer program named Eugene convinced 33\% of the Judges at the Royal Society in 


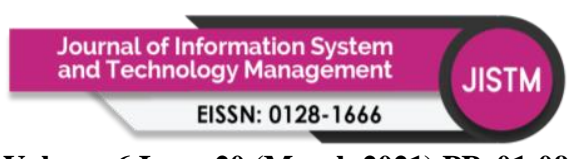

Volume 6 Issue 20 (March 2021) PP. 01-09 DOI: 10.35631/JISTM.620001

London that it was human. From this incident, we humbly assert that computer programs or artificial intelligence units are capable of duping humans into believing that they are humans.

(John Searle, 2004) a philosopher who wrote a paper Mind, Brains and Programmes first published in Behavioural and Brain Sciences in 1980 brought forward The Chinese Room argument. The Chinese room argument applies only to digital computer running programs and does not apply to machines in general. The author (Lawrence B Solum, 1992) made a reference to John Seale theory which questioned the Turing test and put forward an experiment known as The Chinese Room. "Imagine that you are locked in a room. Into the room come batches of Chinese writing, but you do not know any Chinese. You are however given a rule book written in English, in which you can look up the bits of Chinese characters, by their shape. The rule book gives you a procedure for producing strings of Chinese characters that you send out of the room. They are convinced that whatever is in the room understands Chinese, but you do not know a word in Chinese, you are simply following a set of instructions (which we can call a program) based on the shape of the Chinese symbols."

Searle is of the opinion that this experiment demonstrates that neither you, nor the instruction book being the program understand Chinese even though you and the program can simulate such understanding.

From his view, there is a humble understanding that Artificial Intelligence programmes may simulate an understanding on the task in which it is programmed for, but to say that it has a complete understanding, discernment and consciousness would be farfetched. We agree with Seale's view that thinking cannot be attributed to a computer, on the basis of its running a program, that happens to manipulate symbols in a way, that simulates human intelligence and we agree with Seale's argument that a computer program is inadequate in the area of intentionality, that is the ability to process meanings.

\section{$2^{N D}$ Legal issue The Criminal Liability of Artificial Intelligence}

According to (Salt City, 1981)it examines the casualty of Artificial Intelligence namely Kenji Urada who was a Japanese engineer in a Kawasaki Heavy Industries Plant that was killed by a robot who pushed him into a grinding machine with its hydraulic arm and according to (Philadephia Enquirer, 1983)worker at a Ford Motor Company factory in Michigan by the name of Robert Williams was killed by an industrial arm and he was struck in the head two years earlier, on January 25, 1979. And according to (Business Insider, 2015) the jury was awarded \$ 10 million to the heirs. Wanda Holbrook, a freelance maintenance technician in Ventra Ionia Mains plant was killed by a rogue robot, which killed her by crushing her head on July 7, 2015. Business Insider also reported a robot killing of a factory worker at a Volkswagen plant in Germany and the unnamed 21-year-old worker was installing the robot when it struck him on the chest and crushes him against a plate. Who is to be held liable for all this killing? Whether a specific entity has criminal liability or not, one has to prove two elements namely actus reus (Criminal conduct), while the other is the mental element such as knowledge or intent (mens rea). Actus reus as defined (Sherman Dictionary of Law, 1998), is the element of an offence excluding those which concern the mind of the accused. Whereas mens rea means criminal intention or guilty mind. Both elements has to present in order to prove criminal liability. 


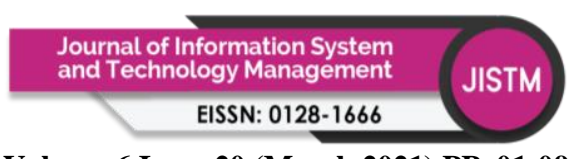

Volume 6 Issue 20 (March 2021) PP. 01-09 DOI: 10.35631/JISTM.620001

If we look at the incidents of murder committed by a robot, it is easy to prove the act or murder by the robots actions, but when we examine the element in actus rea in robots, we do question the act in itself done by the robot was it voluntary or was the act programmed? If we look at Artificial Intelligence model itself, based on many views it is not a person and therefore Artificial Intelligence does not have a mind to control its actions. Therefore, how can an Artificial Intelligence model control itself, because it does not have a mind to think unlike humans? It is so hard to ascertain whether the act committed by the robot was voluntary because Artificial Intelligence is a programme. Artificial intelligence is a machine and never human. In the case of ( $\mathrm{R} v$ Kemp, 1957) the accused was suffering from hardening of the arteries which led to congestion of blood in the brain. He had struck his wife violently with the hammer and the court found Kemp guilty but insane. How about robots that kill human? Can arguments be brought to the court later on that the robots act was involuntary due a program malfunction or the program was corrupted? Then again a robot is not a person based on many views. So, who is criminally liable to the murder committed by the robot?

Mens rea on the other hand is a guilty mind or knowledge on the wrongfulness of the act based on knowledge and intention. How is one to prove intent and knowledge when it involves a robot? Can intent be derived from the programmer of the Artificial Intelligence software or the end user? If an artificial Intelligence model commits a murder and the intent come from the Software Programmer, then the programmer fulfils the element of mens rea. But the act itself is done by the robot and not the programmer, therefore the robot commits the actus reus. But in criminal liability both the element of actus reus and mens rea has to be present.

(Gabriel Hallevy,2010) in his article The Criminal Liability of Artificial Intelligence Entities attempted to come up with models on Criminal Liability. The first model was the perpetration by another Liability model, in which this model failed as this model is a circumstance, when an offense is committed by an innocent agent such as an artificial intelligence model that was programmed by a software programmer to commit a crime. There can be two candidates namely the programmer of the IT software and the second is the end user who uses the Artificial Intelligence and is the master mind behind the Artificial Intelligence unit. Example, A programmer designs a software to torch the factory at night, the robot did the actus reus, but the mens rea came from the programmer and he is the perpetrator and another circumstance is when the end user commands the robot to assault his enemy, the assault or actus reus is committed by the robot but the mens rea came from the end users who gave the command thus being the perpetrator. This model failed because in both incidents the robot committed the crime and the actus reus but in court one will not be able to prove the mens rea came from the robot as well.

\section{3rd Legal Issue Is Whether Robots Can Take Over The Role of Lawyers?}

Another legal issue faced by the legal fraternity is whether the attempt to develop programmes which give advice on the application of law to a user's particular legal problem. The system is known as "legal experts systems" or also could be called computerised legal advisory systems. According to (Graham Greenleaf,1989), expert systems are computer programmes which perform the perplexed task expected of a human expert. There are voluminous research literature and now legal experts are publishing their work on a disk. There are numerous knowledge-based applications relevant to the legal practice. The two features of these knowledge-based applications distinguish them from data based legal applications. The primary components of legal databases are the raw material of legal decisions, cases and 


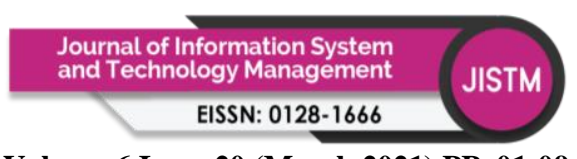

Volume 6 Issue 20 (March 2021) PP. 01-09 DOI: 10.35631/JISTM.620001 statutes, the primary components of knowledge based systems are representations of legal knowledge, information about the legal system (which includes cases and statutes) that has been interpreted by legal experts who created the system. On the other hand, data based systems merely retrieve raw material that are said to be relevant to a particular legal problem which users wish to solve and this knowledge based system apply that raw material to the problem producing an outcome such as an advice or a document which deals specifically with the problem. (Waterman,1986) disagreed with robots taking over the job of lawyers. To quote (Waterman, 1986):

“.... This characteristic of the legal domain having rules that already exist has led to trouble. The problem this creates is the naïve notion (for some) that because a body of rules and regulations exist, all one has to do is to translate them into executable code to create a program for performing complex legal reasoning. He goes on to say that:

"Legal experts use many different kinds of reasoning processing ranging from the if- then rules to analogical reasoning."

\section{Opportunities of Artificial Intelligence}

If we examine the opportunities of Artificial Intelligence it is vast namely Tesla the first drive less car introduced to the world. It is controlled by an Artificial Intelligence system that is able to navigate and self-drive to its destination. Ford also have joined the band wagon by cooperating with Lyft s transportation Network Company and deciding to introduce a hybrid autopilot car in the year 2021. Amazon and Taobao and the trailblazers to adopt Artificial Intelligence technology in the E- Commerce industry. Their online shopping allows 24-hour service to the consumer and allows them to predict the consumer's interest based on their online behaviour. In Malaysia, there are few examples of the opportunities namely the Malaysian Digital Economy Corporation that have collaborated with Alibaba cloud to launch the project "The city Brain." The city Brain project originated from Hangzhou. And this project will pick up on traffic condition, weather routes and public transportation from the CCTV that has been installed enabling drivers to reach their destination in the shortest time (Alibaba Cloud, 2018). This application of Artificial Intelligence on traffic had been proven to increase traffic speed up to $15 \%$ and reduce the arrival time by half of the original time which in turn bring positive impact to urban areas such as Kuala Lumpur and Petaling Jaya (Tan, 2018). The palm oil industry in Malaysia has also adopted Artificial Intelligence through the usage of drones that are able to assess the healthiness of the palms by measuring the moisture of the trees (The Star Online, 2015) and this drones eradicates the hassle of tree counting and terrain measuring.

\section{Conclusion}

From the article, we can conclude that Artificial Intelligence does not have a legal personality of its own, because it lacks many attributes of a human being. It lacks discernment in knowing right from wrong, it lacks empathy, it lacks knowledge, it lacks feelings, and it lacks intentionality. And it is very difficult to prove criminal liability when it involves a robot committing a crime, because a robot may commit the actus reus, the act itself of the crime, the mens rea of the crime namely the mental element of the crime is very difficult to be proven. There are many questions to this very complex Artificial Intelligence model. As far as robot becoming lawyers it is still a farfetched ambition because robot will be able to match legal problems with solutions, but far as thinking and legal reasoning is concern robots will not be able to match human lawyers. The usage of Artificial Intelligence in many industries have 


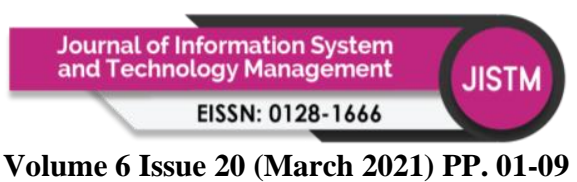

Volume 6 Issue 20 (March 2021) PP. 01-09

DOI: 10.35631/JISTM.620001

grown through the years namely the manufacturing Industry. Thus, to conclude Artificial Intelligence has its fair share of opportunities and also it's downside if not monitored. This research is meaningful because it contributes to the body of knowledge and on the legal personality and criminal liability of Artificial Intelligence. This research also adopts the doctrinal legal research on examining the legal definition of Artificial Intelligence from various law Dictionaries and also jurisprudential approaches and views from various legal scholars on the stance on the legal personality of Artificial Intelligence models.

\section{References}

Alibaba cloud launches Malaysia City Brain to enhance City management (2018) https://www.alibabacloud.com/press-room/alibaba-cloud-launches-malaysia-citybrain-to-enhance-city-management

Andrew. G. (2017) Facebook's Artificial Intelligence robot shutdown after they start talking to each other in their own language. Independent Monday July $31^{\text {st }} 2018$.

AR Damasio Descartes.(1994) Error: Emotion, Reason and the Human Brain (GP Putnam NY) Benjamin D Allgrove. Magdelen College. (2017). Dissertation for the Degree of Master of Philosophy submitted in the University of Oxford entitled: Legal Personality for Artificial Intellects: Pragmatic Solution or Science Fiction?,pg 1

BBC News. (2016) Tesla says autopilot involved in second hand car crash-BBC News https://www.bbc.com/news/technology-36783345

Bringsjord,S. \& Schimanski,b. (2003) What is Artificial Intelligence? Psychometric AI as answer : International Joint Conference of Artificial Intelligence https://www.ijcai.org/Proceedings/03/Papers/128.pdf

Cole David (Fall 2004). " The Chinese Room Argument, In Zalta Edward N The Stanford Encylopedia of Philosophy. https:// plato. Stanford. Edu

Gabriel Hallevy. (2010) The Criminal Liability of Artificial Intelligence Entities, Page 12 obtained from http;ssrn.com

http://www.huffingtonpost.ca/sheryl-boswell/ai-in-the-workplace_b_16108406.html

IEEE Spectrum: Technology, Engineering and Science News (2016) Google's Eric Schmidt says AI will make him smarter, Cooler https://spectrum.ieee.org/automaton/robotics/artificial-intelligence/google-ericschmidt-ai

John R Seale. (1984) Minds, Brains and Science 28-41

J.W.C Turner (19 ${ }^{\text {th }}$ edition 1966) Kenny's Outlines of Criminal Law, page 17

Lawrence B Solum. (1992). Legal Personality for Artificial Intelligences, North Carolina Law Review Vol 70,pg 1236

L.B Curzon. (1989). Dictionary of Law Third Edition, International Law Book Services, , page 257

Michael Anderson, Susan Leigh Anderson (2011). Machine Ethics and A more than Human Moral World. pg119

Nathan McAlone (July 1, 2015). A robot killed a factory worker in Germany www.business insider.com

Nilsson, N.J. (2016) Human level Artificial Intelligence? Be serious! https://www.aaai.org/ojs/index.php/aimagazine/article/view/1850

Owen J Flanagan Jr. (1991). The Science of the Mind. $2^{\text {nd }}$ Edition. 1-22

R v Kemp (1957) 1 1QB 399 
Volume 6 Issue 20 (March 2021) PP. 01-09 DOI: 10.35631/JISTM.620001

Robert W. (2014) From the Guardian Archive, 9 December 1991: Robot kills factory workerThe Guardian https://www.theguardian.com/theguardian/2014/dec/09/robot-killsfactory-worker

Rusell. S.J. \& Norrwig p. (1995) Artificial Intelligence. A modern Approach Retrieved January 18,2018

Salt City UT. (December 8, 1981). Killer Robot Japanese Worker first victim of Technological revolution Deseret News, pg 1

Sherman Dictionary of Law. (1998) Golden Books Centre Sdn Bhd, Kuala Lumpur, , page 14

Sinha and Dheeraj. (1996) Legal Dictionary, Clear Defined legal words and Phrases, Selected Latin Terms and Maxims of Law, International Law Book Series, page 19

Tan. D (2018) Alibaba brings “ city Brains traffic control system to k1 https://paultan.org/2018/01/30/alibaba-to-set-up-ai-traffic-control-system-for-kltraffic/

Tim Kiska, Philadelphia Inquirer. (August 11 1983.)Death on Job: Jury awards \$ 10 million to heir of a man killed by a robot at auto plant, nl.newsbank.com

Weller (2017) A robot that once said it would destroy humans' just became the first robot citizen https://www.businessinsider.com.au/sophia-robot-citizenship-in-saudi-arabiathe-first-of-its-kind-2017-10

$9^{\text {th }}$ June 2014Computer AI Passes Turing Test in world first, www.bbc.com 